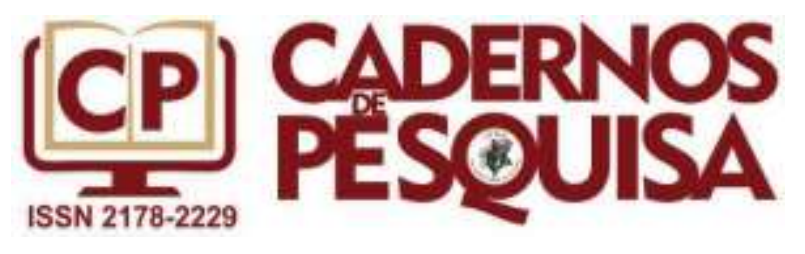

\title{
A INICIAÇÃO À PRÁTICA PROFISSIONAL NA LICENCIATURA EM CIÊNCIAS DA EDUCAÇÃO NA UNIVERSIDADE DE ÉVORA - RELATOS DE UMA EXPERIÊNCIA ${ }^{1}$
}

\author{
INTRODUCTION TO PROFESSIONAL PRACTICE IN \\ EDUCATIONAL SCIENCES DEGREE AT EVORA UNIVERSITY \\ - REPORTS FROM AN EXPERIENCE \\ INICIACIÓN A LA PRÁCTICA PROFESIONAL EN LA \\ LICENCIATURA EN CIENCIAS DE LA EDUCACIÓN EN \\ LA UNIVERSIDAD DE ÉVORA - INFORMES DE UNA \\ EXPERIENCIA
}

Jorge Bonito ${ }^{2}$

ORCID: http://orcid.org/0000-0002-5600-0363

Paulo Costa ${ }^{3}$

ORCID: http://orcid.org/0000-0003-3650-5492

Maria de Lurdes Moreira ${ }^{4}$

ORCID: http://orcid.org/0000-0002-7930-1214

\begin{abstract}
Resumo: O curso de Licenciatura em Ciências da Educação da Universidade de Évora foi apresentado à comunidade académica, na sua primeira edição, no ano escolar de 2007-2008. Decorridos cinco anos de exercício, o curso foi reestruturado, no sentido de se uniformizar o número de créditos de cada unidade curricular (UC), de incluir no plano de estudos um conjunto partilhado de UCs designadas como "propedêuticas" e
\end{abstract}

1 O texto segue a ortografia portuguesa, nos termos do Novo Acordo Ortográfico, ratificado por Portugal em 2008.

2 Centro de Investigação em Educação e Psicologia e Escola de Ciências Sociais da Universidade de Évora. Centro de Investigação em Didática e Tecnologia na Formação de Formadores da Universidade de Aveiro, Portugal

3 Centro de Investigação em Educação e Psicologia e Escola de Ciências Sociais da Universidade de Évora, Portugal.

4 Escola de Ciências Sociais da Universidade de Évora, Portugal 
outras como "transversais" e de diminuir o elenco de UCs optativas existente. Este trabalho tem como objetivo relatar a experiência curricular da iniciação à prática profissional (IPP) introduzida nas UCs de Seminário de Desenvolvimento de Projetos (SDP) e de Projetos de Intervenção em Educação (PIE), enquanto espaços potenciadores do contacto com o mundo do trabalho. No plano metodológico, optou-se por um desenho de matriz qualitativa: para a caraterização da UC de SDP e da UC de PIE, foram analisados documentos oficiais da Universidade de Évora, bem como informação procedente dos inquéritos de opinião dos alunos, no âmbito do Sistema Interno de Promoção e Garantia da Qualidade da Universidade de Évora. No que diz respeito à IPP, optou-se por realizar uma entrevista qualitativa com alunos destas duas UCs, no final do ano escolar de 2019-2020 ( $N=7)$ e às entidades de acolhimento $(N=8)$, tendo como matriz uma análise SWOT sobre o seu funcionamento. Os resultados apontam para a possibilidade de as aprendizagens realizadas no espaço universitário poderem ser mobilizadas em contexto real terem vindo a ganhar consistência. Está por otimizar a articulação entre os membros das equipas docentes, a adaptação dos alunos às instituições e a consolidação das aprendizagens prévias, mas há um conjunto de oportunidades a não descurar.

Palavras-chave: Ciências da Educação; Iniciação à prática profissional; Entidades parceiras.

Abstract: The degree in Educational Sciences at the University of Évora was first presented to the academic community, in the 2007-2008 school year. After five years, the course was restructured in order to standardize the number of credits for each curricular unit (CU), by the inclusion in the curriculum of a shared set of CUs designated as "propaedeutic" as well as other designated as "transversal" and also by decreasing the existing list of optional CUs. This paper aims to report the curricular experience from initiation to professional practice (IPP) introduced in the CUs of Project Development Seminar (PDS) and Intervention Projects in Education (IPE), as spaces that enhance contact with the world of work. At the methodological level, a qualitative matrix design was chosen: for the characterization of PDS and IPE, official documents from the University of Évora were analyzed, as well as information resulting from students' opinion surveys, within the scope of the Internal System of Quality Promotion and Assurance of the University of Évora. With regard to IPP, it was decided to conduct a qualitative interview with the students of these two CUs, at the end of the 2019-2020 school year $(\mathrm{N}=7)$ and with the host entities $(N=8)$, based on a SWOT analysis on how it works. The results point to the possibility that the learning carried out in the university space can be mobilized in a real context, having been gaining consistency. The articulation between the members of the teaching teams, the adaptation of students to the institutions and the consolidation of previous learning, is yet to be optimized, but there are a number of opportunities not to be neglected.

Keywords: Educational sciences; Introduction to professional practice; Partner entities.

Resumen: El curso de primero ciclo en Ciencias de la Educación de la Universidad de Évora se presentó a la comunidad académica, en su primera edición, en el año escolar 2007-2008. Transcurridos cinco años de ejercicio, el curso ha sido reestructurado, con el fin de estandarizar el número de créditos de cada unidad curricular (UC), para incluir en el plan de estudios un conjunto compartido de UCs designado como "propedéuticas" y otras "transversales", disminuyendo simultáneamente la lista existente de UCs opcionales. Este trabajo tiene como objetivo reportar la experiencia curricular desde la iniciación a la práctica profesional (IPP) introducida en las UCs de Seminario de Desarrollo de Proyectos (SDP) y de Proyectos de Intervención en Educación (PIE), como espacios que potencian de contacto con el mundo del trabajo. A nivel metodológico, se eligió un diseño de matriz cualitativa: para caracterizar las UCs de SDP y UC de PIE se analizaron documentos oficiales de la Universidad de Évora, así como información obtenida a través de las encuestas de opinión a los estudiantes, en el ámbito de sistema interno de promoción y seguramiento de la calidad de la Universidad de Évora. En cuanto a la IPP, se decidió realizar una entrevista cualitativa con los alumnos de estas dos UCs, al final del curso 2019-2020 ( $N=7)$ y con las entidades anfitrionas $(\mathrm{N}=8)$, con una matriz de análisis SWOT sobre su funcionamiento. Los resultados apuntan a la posibilidad de que los aprendizajes realizados en el espacio universitario puedan movilizarse en un contexto real, habiendo ido ganando consistencia. La articulación entre los miembros de los equipos docentes, la adaptación de los estudiantes a las instituciones y la consolidación de los aprendizajes previos aún está por optimizar, pero hay una serie de oportunidades que no se deben desaprovechar. 
Palabras-clave: Ciencias de la Educación; Iniciación a la práctica profesional; Entidades parceras.

\section{INTRODUÇÃO}

No início da década de 1970, o Governo Português definiu um plano de expansão e diversificação do ensino superior para corresponder à necessidade de assegurar o desenvolvimento social e económico do país, que exigia um número cada vez mais elevado de cientistas, técnicos e administradores de formação superior, dotados de capacidade crítica e inovadora. Em 1973, é criado o Instituto Universitário de Évora (Decreto-Lei n. ${ }^{\circ}$ 402/73, de 11 de agosto), definido, essencialmente, como uma instituição de ensino universitário que se individualiza por ter uma vocação dominante ou um grau de pluridisciplinaridade limitado, pese embora sendo-Ihe aplicáveis todas as disposições para as novas Universidades, nesta data criadas5. Em 1979, o perfil institucional do Instituto Universitário de Évora já não correspondia ao que fora apresentado como caraterístico dos institutos universitários, pelo que, em 14 de dezembro de 1979, o Governo decreta extinguir o Instituto Universitário de Évora e cria a Universidade de Évora (UÉ), para a qual transfere todos os direitos e obrigações de que aquele era titular (Decreto-Lei n. ${ }^{\circ}$ 482/79, de 14 de dezembro). A Universidade de Évora permanece, desde a sua criação, como a única universidade pública da região do Alentejo ${ }^{6}$.

O curso de $1 .^{\circ}$ ciclo $^{7}$ em Ciências da Educação da UÉ foi apresentado à comunidade académica, na sua primeira edição, no ano escolar de 2007-2008. Decorridos cinco anos de exercício, por indicação superior da Escola de Ciências Sociais, o curso foi reestruturado, no sentido de se uniformizar o número de créditos de cada unidade curricular (UC), de se incluir no plano de estudos um conjunto partilhado de UCs designadas como "propedêuticas" e outras como "transversais" e de se diminuir o elenco de UCs optativas existente (que, desde a primeira edição, era em número de 37). A nova estrutura e o renovado plano de estudos (publicado pelo Despacho n. ${ }^{\circ}$ 9204/2012, de 9 de julho), colocado em execução a partir do ano escolar 2012-2013, foi acreditado pela Agência de Avaliação e Acreditação

5 Nesta data, em Portugal, foram criadas a Universidade Nova de Lisboa, a Universidade de Aveiro e a Universidade do Minho (art. $8 .^{\circ}$ do Decreto-Lei n. ${ }^{\circ} 402 / 73$, de 11 de agosto).

6 O Alentejo é a maior região de Portugal em termos de área e a $4 .^{a}$ mais populosa do país. Tem uma área total de $31.603 \mathrm{~km} 2 \mathrm{e}$, de acordo com os Censos de 2021, uma população de 704.934 habitantes (densidade de 22,3 hab/km2). Tem 58 municípios e está dividido em 5 sub-regiões: Alto Alentejo, Baixo Alentejo, Alentejo Central, Alentejo Litoral e Lezíria do Tejo.

$7 \mathrm{O} 1 .^{\circ}$ ciclo de estudos corresponde ao primeiro grau académico conferido pelas instituições de ensino superior de Portugal, designado de licenciado. Trata-se do equivalente brasileiro de bacharelato. Tem uma duração normal entre 6-8 semestres com 180-240 créditos no Sistema Europeu de Transferência e Acumulação de Créditos (European Credit Transfer and Accumulation System Credits - ECTS) (Decreto-Lei 74/2006, de 24 de março). Os créditos ECTS medem o volume de trabalho do estudante de uma forma mais relativa do que absoluta (CE, 2020). No quadro do ECTS, 60 créditos representam o volume de trabalho de um ano de estudos. Regra geral, 30 créditos equivalerão a um semestre e 20 créditos a um trimestre de estudos. 
do Ensino Superior (A3ES) e posteriormente registado pela Direção-Geral do Ensino Superior com o n. ${ }^{\circ} \mathrm{R} / \mathrm{A}$ - CR 56/2012.

Este curso confere o grau de licenciado, nos termos do art. $5 .^{\circ}$ do Regime Jurídico dos Graus e Diplomas do Ensino Superior (aprovado pelo Decreto-Lei n. ${ }^{\circ} 74 / 2006$, de 24 de março, na sua redação atual), com a atribuição de 180 créditos no sistema europeu de transferência e acumulação de créditos. A área científica predominante do curso é a de Ciências da Educação e a sua duração normal é de três anos, organizados em seis semestres.

Aprender a fazer é algo novo e difícil, particularmente no início de uma carreira profissional. Ainda que a formação académica seja o alicerce estrutural das práticas, parece tácito que o único modo de aprender algo novo é praticando. Gladwell (2008) sugere que se leva cerca de $10.000 \mathrm{~h}$ de prática para se tornar um especialista em algo. Kaufman (2012), talvez um pouco mais realista, avança que ir de não saber fazer nada até ser muito bom, implica cerca de 20 horas de prática, isto é, 45 min todos os dias. Para além desta ou de outra contagem de horas de prática, o que nos parece claro é que alguém que aspira a ser muito bom ou especialista numa determinada área, a prática - de modo reiterado - é absolutamente essencial. Mas o processo pode ser difícil se estamos habituados a baixos níveis de proficiência. É relativamente fácil admirar as competências de alguém (por exemplo, um médico especialista, um atleta nadador, um instrumentista) sem ter presente o número de horas que essa pessoa dedicou à prática e ao treino, até chegar ao estado em que o encontramos.

Podemos captar rapidamente ideias e conceitos, levando-nos a acreditar que sabemos colocá-los em ação. Mas se não os praticamos, efetivamente, nunca se chega a um nível de desempenho elevado. E não se pode esperar que nos primeiros estádios da prática a proficiência seja elevada: acreditar nisso seria uma ilusão.

A iniciação prática profissional (IPP) poderá ser definida como o exercício temporário de uma profissão sob a supervisão de um tutor ou professor. Daí que, amiúde, seja muitas vezes o primeiro passo para um aluno, ou um recém-formado, no mercado de trabalho. Esta etapa formativa, combina questões típicas de um posto de trabalho, como, por exemplo, integrar uma equipa de trabalhadores, atingir um certo nível de produtividade, estar sujeito aos poderes de direção e de regulamentação. Para uma sociedade comercial, a oferta de um estágio profissional é interessante e essencial. Cria-se a oportunidade de formar colaboradores que podem vir a integrar o seu quadro permanente. Além disso, constitui uma boa forma de poupar custos. Os estagiários podem trabalhar ad honorem ou até receber uma remuneração simbólica, apesar do cumprimento de tarefas importantes no dia-a-dia da empresa (GALLOWAY; MARKS; CHILLAS, 2014; HOLYOAK, 2013). Do ponto de vista do aluno, o acesso a um estágio profissional proporciona-lhe uma excelente e inapreciável oportunidade de se introduzir no mercado de trabalho e de adquirir um know how que a formação académica não permeia. 
Muitos estudos apontam que o conhecimento teórico e teórico-prático que as instituições de ensino superior proporcionam representa apenas uma pequena parte do conhecimento geral e das habilidades necessárias para os alunos encontrarem um emprego após os seus estudos (GARCÍA-ARACIL; MONTEIRO; ALMEIDA, 2018; FARIAS; SILVA, 2014; ŠIMIČEVIČ; ŠTETIĆ, 2017). Em conformidade, a IPP tem assumido grande importância no plano curricular de cursos das mais variadas áreas. As práticas em contexto de trabalho permitem que os alunos desenvolvam competências interpessoais, de trabalho em equipa, iniciem o seu desenvolvimento profissional e se relacionem com clientes ou usuários da entidade. Melhoram a sua comunicação, a confiança nas suas aprendizagens, no seu potencial e na sua autoeficácia. Saniter e Siedler (2014) destacam que os alunos que têm oportunidade de desenvolver experiências de estágios apresentam mais probabilidade de encontrar empregos e de obter melhores salários.

Ismail (2019) interrogou-se acerca dos benefícios dos programas de estágio em matéria de melhorias percebidas nas habilidades e nos resultados da empregabilidade. $\mathrm{Na}$ revisão sistemática da literatura que realizou, concluiu que um programa bem-sucedido que acolha alunos para práticas profissionais requer recursos adequados para estruturar e monitorizar o próprio programa. Parece importante que os alunos sintam algum controlo das suas decisões e tenham senso de autonomia (MCMANUS; FEINSTEIN, 2014). Os alunos devem ser encorajados a enfocar o seu trabalho em objetivos ou tópicos, centrados em algumas áreas, evitando-se a prática da rotatividade por vários setores da entidade anfitriã. Janelas de oportunidade para autorreflexão, que incluam estratégias metacognitivas, permitindo que os alunos monitorizarem o seu progresso, aparecem como estratégias de relevo para regular e modificar o progresso de sua atividade cognitiva. É conveniente a existência de um clima de abertura que permita aos alunos colocarem questões aos seus supervisores, sobre os mais variados aspetos da sua atividade (Plumm, 2018). Este é um processo gradual que pode ser facilitado pelo uso de cadernos de campo ou logs, ferramentas de gestão do tempo e exercícios de autoavaliação (MCMANUS; FEINSTEIN, 2014).

Galloway, Marks e Chillas (2014) apontam que uma atitude positiva entre os alunos estagiários constitui-se como um fator crítico de sucesso. O desenvolvimento de tutorias de alta qualidade, com fornecimento regular de feedback de qualidade, aumenta as taxas de experiências bem-sucedidas. Este valor aumenta quanto na instituição académica um docente acompanha o estágio de modo continuado (VÉLEZ; GINER, 2015). A eficácia do programa também está associada ao facto de se ter o apoio da alta administração da instituição académica e da entidade acolhedora. Por isso, Maertz, Stoeberl e Marks (2014) sublinham que os supervisores devem dedicar tempo suficiente e ter a capacidade para acompanhar o desenvolvimento profissional dos estagiários. Os autores referem que, idealmente, a entidade acolhedora deveria estar disposta a suportar os custos de hospedagem ou de deslocação dos estagiários, uma vez que obtém benefícios com a sua incorporação. 
Por fim, alerta-se para que as expectativas dos estagiários, dos empregadores e da academia sejam realistas e alinhadas entre si.

Em síntese, a IPP deve ser encarada como um momento ímpar para a formação profissional, na medida em que complementa o processo de ensino e aprendizagem, proporcionando ao aluno a "construção de uma postura crítica e reflexiva sobre a realidade em que está inserido" (SILVA; BELO, 2019, p. 565). O envolvimento responsável dos sujeitos no processo de estágio, permite uma formação integrada e superar a dicotomia entre a teoria e a prática. Por isso, a oportunidade de vivenciar trabalhos de campo, ao longo da sua formação superior, permite diminuir a discrepância na perceção dos estudantes entre os conhecimentos adquiridos no curso e a preparação para iniciar a vida profissional (CASH; WILLIAMS; HART, 2020). A monitorização sistemática, por parte dos docentes e das instituições de acolhimento, permite avaliar o progresso dos alunos e detetar, desde uma fase inicial, as dificuldades sentidas, tendo um suporte que thes permite corrigir e suplantar esses deficits em contexto protegido e ao longo do seguimento do curso. O acolhimento por entidades parceiras e um apoio personalizado aos alunos pelas entidades e docentes concorrem para um suporte de qualidade na inserção nas dinâmicas de trabalho em diferentes áreas de aplicabilidade do curso que permite desenvolver a confiança e a proatividade dos alunos.

A existência da IPP num curso de $1 .^{\circ}$ ciclo em educação não é inovadora. Vejamos dois exemplos. A Universidade de Suffolk, no Reino Unido, apresenta UC de IPP como uma oportunidade para os alunos, desde os primeiros anos, desenvolverem uma panóplia de habilidades pessoais, profissionais e académicas que permitam apoiar os seus estudos e melhorar o seu desenvolvimento pessoal e profissional (US, 2020). Em Portugal, a licenciatura em Educação e Formação da Universidade de Lisboa, na UC Análise de Projetos Educativos e Formativos, tem previstos três momentos presenciais de visita às instituições para observação e caraterização das mesmas, para recolha de dados sobre o seu projeto educativo ou formativo e para entrevistas a informantes privilegiados sobre a conceção, desenvolvimento e avaliação do referido projeto. Na UC Seminário 5 - Conceção de um Projeto de Intervenção, os alunos realizam a sua intervenção nas instituições educativas / formativas em equipas de dois ou três elementos, devendo ter uma presença semanal entre 4 a 6 horas, aumentando a sua presença para 8 a 10 horas na UC Seminário 6 - Desenvolvimento e Avaliação de um Projeto de Intervenção (UL, 2020).

Este trabalho tem como objetivo relatar a experiência curricular da IPP introduzida na UC de Seminário de Desenvolvimento de Projetos (SDP) e na de Projetos de Intervenção em Educação (PIE), da licenciatura em Ciências da Educação da UÉ, no período entre 2014 e 2019, apontando-se linhas de melhoramento.

\section{METODOLOGIA}


Para a realização deste trabalho optou-se por um desenho metodológico de natureza qualitativa, que permitisse triangular informação proveniente de diversas fontes, para a construção de uma conceção múltipla da realidade, mediante o uso de técnicas interativas e indiretas (COLÁS, 1998). Para a caraterização da UC de SDP e da UC de PIE, fez-se análise de documentos oficiais da UÉ e de informação procedente dos inquéritos de opinião dos alunos, no âmbito do Sistema Interno de Promoção e Garantia da Qualidade da UÉ. No que diz respeito à IPP, optou-se por realizar uma entrevista qualitativa com alunos destas duas UCs, no final do ano escolar de 2019-2020 (N=7) e com as entidades de acolhimento $(\mathrm{N}=8)$, tendo como matriz uma análise SWOT sobre o seu funcionamento. As entrevistas foram transcritas e analisado o seu conteúdo. Foi garantido o anonimato dos respondentes.

\section{RESULTADOS}

\subsection{AS UNIDADES CURRICULARES DE SDP E PIE}

A alteração à estrutura e ao plano de estudos do curso de $10^{\circ}$ ciclo em Ciências da Educação constituiu a oportunidade de se criar algo que os alunos do plano anterior vinham a reclamar e que os docentes reconheciam como necessidade: a existência de um estágio ou de uma UC que permitisse assegurar algo que se the assemelhasse. Com esse elemento de referência, o novo plano de estudos manteve a UC SDP e introduziu a nova UC de PIE. Amado (2014) defende que:

\footnotetext{
a primeira delas - Seminário de Desenvolvimento de Projetos - visando preparar para a segunda, poderia agora ter uma vertente teórica mais forte do que tinha antes (necessidade reforçada pelo "desaparecimento" no novo plano de estudos de duas UC do plano anterior (Metodologia do Planeamento e Teoria das Organizações). A segunda - Projetos de Intervenção em Educação - poderia ser uma disciplina de "aplicação" (mas não um "Estágio", por este formalmente não poder ser incluído no plano de estudos), uma UC vocacionada para a intervenção multiforme em contextos educativos. (p. 1)
}

A "congeminação" desta nova UC, como lhe chama Amado (2014), terá sido o aspeto que mais cuidado exigiu. A Comissão de Curso, para além do programa da UC, elaborou uma lista de áreas de intervenção que deveriam ser contempladas e de potenciais instituições parceiras (UÉ, 2012b) com as respetivas funções genéricas (UÉ, 2012c). Expectava-se um grande impacte na nova UC de PIE, no valor global do projeto formativo renovado, concebido para uma simbiose da díade disciplinar, explicitamente referido na defesa da coerência dos objetivos definidos com a missão e a estratégia da instituição de ensino (UÉ, 2012a): 
2. O facto de a Universidade se inserir até do ponto de vista da localização dos seus edifícios no tecido social da cidade de Évora favorece a aposta, que é um dos pontos fortes desta reformulação curricular que, sem querer, pelo contrário, diminuir a solidez da formação científica básica, visa reforçar a procura de parcerias no terreno local e regional que permitam aos estudantes fazer uma iniciação à prática profissional designadamente, mas não só, nas UC terminais de Seminário de Desenvolvimento de Projetos e de Projetos de Intervenção em Educação, esta última em regime de polidocência de forma a poder proporcionar acompanhamento específico de cada estudante relativamente aos seus Projetos. (3.1.3)

Assim, no formulário submetido à A3ES, para acreditação do curso, indica-se, de modo sumário, que a metodologia de trabalho da UC de SDP é a "de seminário, no sentido de orientar o desenvolvimento de um projeto real" (UÉ, 2012a, 3.3.7). Por isso, a classificação da disciplina resultaria da realização do trabalho prático, que consistiria na elaboração de um projeto real, sendo a classificação final consequente da apreciação das diferentes etapas conducentes ao desenvolvimento de um projeto (pontos de partida, planificação, desenvolvimento, avaliação). Previa-se, ainda, que esta UC fosse assegurada por um único docente.

Relativamente à UC de PIE, no formulário submetido à A3ES, indica-se que a sua finalidade é "fornecer aos estudantes que a frequentarem a capacidade de participar no processo de conceção, implementação e avaliação de projetos de educação e formação em contexto real, devidamente enquadrados em instituições que os promovam" (UÉ, 2012a, 3.3.6). Para o efeito, a abordagem metodológica assentaria na "participação discente em projetos concretos de educação e formação promovidos por instituições locais ou regionais de diferentes naturezas (autarquias, serviços públicos, associações, escolas, museus, empresas, centros de investigação, etc.)", sendo a aprendizagem discente "devidamente acompanhada por uma equipa de docentes e por elementos das instituições de acolhimento" (UÉ, 2012a, 3.3.7).

Por isso, ao nível da avaliação, prevê-se ter em conta a "qualidade e a regularidade do trabalho produzido pelos estudantes" que "resultará da observação direta do trabalho desenvolvido e da análise de portefólios descritivos do processo de aprendizagem concretizado" (UÉ, 2012a, 3.3.7). Neste caso, prevê-se para a UC de PIE uma equipa composta por 11 docentes, todos do Departamento de Pedagogia e Educação da Escola de Ciências Sociais.

Numa análise SWOT, realizada ao novo ciclo de estudos pela Comissão de Curso, prevê-se como constrangimentos (UÉ, 2012a):

1. Dificuldades de coordenação de todos os docentes envolvidos. 2. As eventuais dificuldades de colocar em funcionamento a nova Unidade Curricular de Projetos de Intervenção em Educação, embrião daquilo que pode ser considerado um practicum, a exigir o estabelecimento de parcerias com atores variados no campo da educação e da formação. O caminho pode ser, no entanto, facilitado neste aspeto 
pela dimensão da cidade e pela existência de boas relações interinstitucionais no plano local e regional. (12.4)

A nova proposta do novo ciclo de estudos é aprovada em maio de 2012 e colocada em execução no ano escolar de 2012-2013. SDP é uma UC obrigatória da área das ciências da educação, com 6 créditos, prevista no plano de estudos para o $3 .^{\circ}$ ano $/ 5 .^{\circ}$ semestre. Tem 156 horas de trabalho: 61 horas de contacto com o docente (60 horas teórico-práticas e 1 hora tutorial) e 95 horas de trabalho autónomo.

A UC de PIE, da área científica das ciências da educação, realiza-se no $3 .^{\circ}$ ano / $6 .^{\circ}$ semestre. Tem caráter obrigatório e desenvolve-se com o mesmo número de horas que a UC SDP. No Quadro 1 apresentam-se os objetivos, conteúdos programáticos e metodologias de ensino destas UC.

Quadro 1 - Objetivos, conteúdos programáticos e metodologias de ensino das UCs SDP e PIE.

\begin{tabular}{|c|c|}
\hline $\begin{array}{c}\text { SEMINÁRIO DE DESENVOLVIMENTO } \\
\text { DE PROJETOS }\end{array}$ & $\begin{array}{c}\text { PROJETOS DE INTERVENÇÃO } \\
\text { EM EDUCAÇÃO }\end{array}$ \\
\hline \multicolumn{2}{|c|}{$\begin{array}{l}\text { OBJETIVOS } \\
\end{array}$} \\
\hline $\begin{array}{l}\text { 1. Conhecer o processo do desenvolvimento de } \\
\text { projetos. } \\
\text { 2. Construir e aplicar competências, no âmbito do } \\
\text { desenho e conceção de projetos. } \\
\text { 3. Construir e aplicar competências, no âmbito da } \\
\text { concretização de projetos. } \\
\text { 4. Avaliar projetos. }\end{array}$ & $\begin{array}{l}\text { 1. Conhecer exemplos concretos de projetos de } \\
\text { educação e formação de âmbito local ou regio- } \\
\text { nal. } \\
\text { 2. Aplicar os conhecimentos e as competências } \\
\text { construídos ao longo da componente curricular } \\
\text { em projetos de educação e formação promovi- } \\
\text { dos por instituiçães locais ou regionais. } \\
\text { 3. Participar na elaboração, concretização e } \\
\text { avaliação de projetos de educação e formação } \\
\text { concretizados em situação real. } \\
\text { 4. Avaliar da importância da educação e forma- } \\
\text { ção em diversas dimensões da atividade institu- } \\
\text { cional. } \\
\text { 5. Conhecer e avaliar diversos contextos profis- } \\
\text { sionais na área das ciências da educação. }\end{array}$ \\
\hline \multicolumn{2}{|c|}{ CONTEÚDOS PROGRAMÁTICOS } \\
\hline $\begin{array}{l}\text { 1. Caraterização de projetos } \\
\text { 1.1. Projetos de intervenção } \\
\text { 1.2. Projetos de investigação } \\
\text { 1.3. Projetos de investigação-ação } \\
\text { 2. Desenvolvimento de projetos } \\
\text { 2.1. Pontos de partida de um projeto. Identificação } \\
\text { de problemas e diagnóstico. } \\
\text { 2.2. Definição de objetivos } \\
\text { 2.3. Definição de estratégias } \\
\text { 2.4. Programação das atividades } \\
\text { 2.5. Plano de avaliação } \\
\text { 2.6. Divulgação de resultados } \\
\text { 3. Avaliação de projetos } \\
\text { 3.1. Conceito de avaliação } \\
\text { 3.2. Tipos de avaliação } \\
\text { 3.3. Conteúdos da avaliação }\end{array}$ & $\begin{array}{l}\text { 1. Os agentes institucionais da educação e } \\
\text { formação } \\
\text { 2. A conceção, concretização e avaliação de } \\
\text { projetos de educação e formação } \\
\text { 3. As redes educativas e sociais dos territórios } \\
\text { 4. A formação profissional }\end{array}$ \\
\hline
\end{tabular}


METODOLOGIAS DE ENSINO

\begin{tabular}{|c|c|}
\hline a em duas componentes: aulas teórico-prátice & $\begin{array}{l}\text { te } \\
\text { i- } \\
\text { ha } \\
\text { de } \\
\text { esen- } \\
\text { n ser } \\
\text { final. } \\
\text { odo: } \\
\text { a IPP } \\
\text { I̧ão } \\
\text { o em } \\
\text { as } \\
\text { ção } \\
\text { ç̃es } \\
\text { lttan }\end{array}$ \\
\hline
\end{tabular}

Fonte: elaboração dos autores com base nas fichas de UC que constam no Sistema de Informação Integrado da Universidade de Évora (SIIUÉ) em agosto de 2020.

A nova UC de PIE entra em funcionamento, pela primeira vez, no ano escolar de 2014-2015, não sem a concretização do expectável constrangimento aventado em 2012, ao nível das dificuldades de coordenação de todos os docentes envolvidos. Em concreto, tornou-se espinhosa a articulação entre a UC de SDP e a de PIE, em particular pela tarefa hercúlea de confrontar a autonomia científica e pedagógica do docente da UC de SDP. O que estava na mesa da discórdia era o reduzo espectro de instituições cooperantes com a UC de SDP e, sobretudo, a natureza dos temas de trabalho definidos a desenvolver, que não estavam "devidamente focados no 'core business' profissional dos Licenciados em Ciências da Educação" (AMADO, 2014, p. 4), que condicionavam toda a programação da UC de PIE. Tais factos criaram, nesse primeiro ano, desarticulação entre as duas UCs, facto que necessitava de ser corrigido. Aliás, no Relatório Final da Comissão de Avaliação Externa da A3ES (UÉ, 2012d) fica expresso a imprescindível articulação entre as duas UCs. Supostamente, a UÉ terá informado a A3ES da existência de um núcleo comum de três docentes, a que se juntavam mais quatro na UC de PIE, "para garantir que todas as possíveis áreas de prática supervisionada se encontram acauteladas" (p. 13). Presume-se, porém, que tal facto não tenha ocorrido, pelo que fora aqui relatado.

O ciclo de estudos foi alterado em 2019 (Aviso n. ${ }^{\circ}$ 5413/2019, de 28 de março), com efeitos a partir do ano escolar de 2019-2020; ainda assim, sem qualquer alteração à estrutura destas duas UCs.

\subsection{AVALIAÇÃO DA UC SDP E DA UC PIE}

A primeira concretização material do compromisso da UÉ com a qualidade ocorre em 1994, com a criação do Conselho de Avaliação e a Comissão de Acompanhamento da Avaliação. Na década seguinte, a valorização atribuída à avaliação dos cursos e a expe- 
riência adquirida constituem-se os vetores essenciais para a criação de várias pró-reitorias para a avaliação institucional e política da qualidade. É no final desta década que vem a ser aprovado o Programa para a Promoção Institucional da Qualidade da Universidade de Évora, revisto pelo Conselho de Avaliação em 2011.

O estabelecimento do Regime Jurídico das Instituições de Ensino Superior (RJIES) (aprovado pela Lei n. ${ }^{\circ}$ 62/2007, de 10 de setembro) condicionou estas instituições a rever os seus estatutos de modo a conformá-los com o novo ordenamento jurídico. Na revisão estatutária da Universidade de Évora, aprovada pelo Ministro da Ciência, Tecnologia e Ensino Superior, inscreve-se como competência do Reitor "tomar as medidas necessárias à garantia da qualidade do ensino e da investigação na Instituição e nas suas unidades orgânicas" (art. 22..$^{\circ}$ n. ${ }^{\circ} 1$, al. s) do Despacho Normativo n. ${ }^{\circ} 54 / 208$, de 20 de outubro). Na continuação, o Reitor determina a implementação, em 2014, do Sistema Interno de Promoção e Garantia da Qualidade da Universidade de Évora (SIPGP-UÉ/2014.1) através da aplicação do respetivo Manual de Qualidade (GPGUÉ, 2014).

O corpo discente constitui um subcampo de análise, do campo ensino, relativo aos indicadores de monitorização de qualidade. Sublinhe-se que o Regime Jurídico da Avaliação da Qualidade do Ensino Superior (RJAQES) (aprovado pela Lei n. ${ }^{\circ} 38 / 2007$, de 16 de agosto) estabelece, como princípio geral, que o sistema de avaliação de qualidade assegura a participação dos estudantes, entre outros modos, através da sua resposta nos inquéritos pedagógicos às UCs, obrigatoriamente integrados no processo de autoavaliação. Nesse sentido, o Manual de Qualidade da SIPGP-UE/2014.1, considera o indicador "índice de satisfação - unidades curriculares", que traduz o "valor global do índice de comparabilidade obtido pela agregação de todas as questões sobre as unidades curriculares, do inquérito de opinião aos alunos" (GPGUÉ, 2014, p. 47).

O inquérito de opinião constitui um instrumento importante de recolha de informação, isenta e anónima, junto dos alunos da UC. A sua construção obedeceu a critérios de rigor e de utilidade, permitindo comparações intertemporais e interinstitucionais. É preenchido nas duas últimas semanas de cada semestre. A análise dos resultados incorpora o relatório da UC elaborado pelo responsável pela UC, até 30 dias após a conclusão do semestre. Os relatórios das várias UCs do curso são analisados pelo diretor de curso, que elabora um relatório anual do ciclo de estudos, um mês após a conclusão do ano escolar, que recebe parecer do diretor do departamento na parte respeitante às UCs desse departamento, com tramitação para o Conselho Pedagógico, que elabora uma síntese de apreciação da qualidade e da adequação do ensino ministrado. Após pronúncia do diretor da escola sobre as recomendações e plano de ação global, o relatório é remetido ao Conselho de Avaliação.

Para a realização do indicador "índice de satisfação - unidades curriculares", são colocadas aos alunos, no SIIUE, um conjunto de sete questões obrigatórias, devendo ser dada oportunidade de ausência de resposta, com a indicação das razões que justificam essa opção, a saber: P4 - Nível de aquisição de conhecimentos; P5 - Acessibilidade da 
matéria em relação aos seus conhecimentos anteriores; P6 - Coordenação entre docentes, se aplicável; P7 - Acesso à bibliografia e fontes de informação recomendadas; P8 - Correspondência entre os conhecimentos avaliados e a matéria lecionada; P9 - Adequação dos métodos de avaliação utilizados; P10 - Importância desta UC na aquisição de competências que pensa serem necessárias para o futuro exercício profissional.

No tratamento da informação recolhida através dos inquéritos de opinião é calculado o índice de comparabilidade (IC) cujos resultados se situam no intervalo de -4 a 4 , determinado com base na média de respostas obtidas para cada pergunta. As opções de resposta são "elevado", "suficiente", "insuficiente" e "reduzido", considerando-se as duas primeiras favoráveis, logo com pontuações 4 e 2 , respetivamente, e as duas últimas indesejáveis, com pontuações 4 e 2 respetivamente. O IC determina-se através da razão entre a diferença da soma das pontuações positivas e da soma das pontuações negativas, e o número de respostas válidas. São considerados resultados insatisfatórios, as situações que se afastem de forma significativa dos objetivos de sustentabilidade e de qualidade da oferta formativa, correspondentes aos casos em que os cursos se encontrem, entre outros critérios, com valor do IC negativo em $50 \%$ ou mais das questões do curso no inquérito de opinião aos estudantes (GPGUÉ, 2014, p. 19).

Na Tabela 1 apresentam-se os resultados do IC relativo à UC SDP, que respeitam aos anos escolares de 2014 a 2019.

Tabela 1 - Resultados do índice de comparabilidade do inquérito aos alunos acerca da UC SDP, relativos aos anos escolares de 2014 a 2019.

\begin{tabular}{lrrrrrr|r|r|r|r|r|r|}
\hline & $\mathbf{2 0 1 4}$ & $\mathbf{2 0 1 5}$ & $\mathbf{2 0 1 6}$ & $\mathbf{2 0 1 7}$ & $\mathbf{2 0 1 8}$ & $\mathbf{2 0 1 9}$ & Média & Mín. & Máx. & Mediana & $\boldsymbol{D} \boldsymbol{P}$ & $\boldsymbol{P 7 5}$ \\
& 12 & 3 & 9 & 7 & 11 & 13 & 9 & 3,00 & 13,00 & 10,00 & 3,39 & 11,75 \\
P4 & 0,83 & 2,00 & 2,89 & 2,29 & 3,27 & 3,08 & 2,39 & 0,83 & 3,27 & 2,59 & 0,83 & 3,03 \\
P5 & 1,33 & 3,00 & 2,89 & 2,29 & 2,73 & 3,17 & 2,57 & 1,33 & 3,17 & 2,81 & 0,62 & 2,97 \\
P6 & $-0,25$ & - & 3,43 & 2,00 & 1,64 & 0,92 & 1,55 & $-0,25$ & 3,43 & 1,64 & 1,22 & 2,00 \\
P7 & 2,18 & 2,00 & 3,33 & 2,00 & 2,73 & 3,08 & 2,55 & 2,00 & 3,33 & 2,46 & 0,53 & 2,99 \\
P8 & 1,67 & 3,00 & 2,89 & 2,33 & 2,73 & 2,33 & 2,49 & 1,67 & 3,00 & 2,53 & 0,45 & 2,85 \\
P9 & 0,67 & 3,00 & 2,89 & 2,67 & 2,73 & 2,00 & 2,33 & 0,67 & 3,00 & 2,70 & 0,81 & 2,85 \\
P10 & 2,50 & 3,00 & 2,89 & 2,86 & 3,27 & 4,00 & 3,09 & 2,50 & 4,00 & 2,95 & 0,47 & 3,20 \\
VGIC & 1,28 & 2,67 & 3,03 & 2,35 & 2,73 & 2,65 & 2,42 & 1,28 & 3,03 & 2,66 & 0,56 & 2,71 \\
\hline
\end{tabular}

Legenda: DP - desvio padrão; P75 - percentil 75; N - número de respondentes; VGIC - Valor Global do Índice de Comparabilidade.

Fontes: SIIUÉ. Elaboração dos autores.

Pese embora a reduzida taxa de respostas (média de 9 alunos), os dados permitem perceber alguns detalhes relevantes relativamente à opinião dos alunos acerca da UC SDP, onde se insere a IPP. O maior VGIC ocorre no ano escolar de $2016(3,03)$ e o menor em $2014(1,28)$, este coincidente com o ano da entrada em vigor da reestruturação do curso. Assiste-se a um crescendo do VGIC entre 2014 e 2016, para em 2017 cair para valor infe- 
rior ao de 2015, voltando a crescer no ano seguinte e, a partir daí, diminuir para 2,65, registado no último ano escolar. Nestes seis anos em apreciação, a média do VGIC é de 2,42.

A importância da UC SDP para a aquisição de competências necessárias para o futuro exercício profissional (P10) congregou o maior IC (média 3,09), com expressão máxima no transato ano escolar $(4,00)$, isto é, neste ano as frequências concentram-se todas nas categorias de respostas "positivas" (elevado e suficiente). O menor valor $(2,50)$ registou-se no ano escolar de 2014. Será preciso descer até 2,57 para encontrar a afirmação que congregou maior número de resposta "positivas": acessibilidade da matéria em relação aos seus conhecimentos anteriores (P5), superior em duas décimas $(2,55)$ relativamente ao acesso à bibliografia e fontes de informação recomendadas (P7). A coordenação entre docentes (P6) corresponde ao aspeto menos favorável, registando o valor médio de 1,55. Note-se que a P6 teve valor negativo em 2014 e, apesar da expressão máxima em 2016 (3,43), a partir daí assiste-se a uma curva decrescente, com o valor de 0,92, registado no último escolar. Ou seja, parece que as dificuldades de coordenação de todos os docentes envolvidos, identificadas na análise SWOT de 2012, se mantiveram, vindo a agudizar-se nos últimos três anos. Sublinhe-se que, no último ano escolar, foram seis os docentes que asseguraram esta UC. Outro aspeto, que parece interessante, é a discrepância entre o nível de aquisição de conhecimentos (P4) e a importância atribuída a esta UC (P10), que distam, entre si, 0,7 pontos.

A questão da avaliação também revela algumas opiniões negativas. Os métodos de avaliação utilizados (P9) não recebem grande favoritismo $(2,33)$, todavia com alguma correspondência entre os conhecimentos avaliados e a matéria lecionada $(2,49)$.

Os resultados do IC relativos à UC PIE, no que diz respeito aos anos escolares de 2014 a 2019, apresentam-se na Tabela 2.

Tabela 2 - Resultados do índice de comparabilidade do inquérito aos alunos acerca da UC PIE, relativos aos anos escolares de 2014 a 2019.

\begin{tabular}{lr|r|r|r|r|r|r|r|r|r|r|r|}
\hline & $\mathbf{2 0 1 4}$ & $\mathbf{2 0 1 5}$ & $\mathbf{2 0 1 6}$ & $\mathbf{2 0 1 7}$ & $\mathbf{2 0 1 8}$ & $\mathbf{2 0 1 9}$ & Média & Mín. & Máx. & Mediana & DP & P75 \\
\cline { 2 - 13 } \\
N & 18 & 5 & 11 & 13 & 13 & 14 & 12 & 5 & 18 & 13 & 3,90 & 13,75 \\
P4 & 2,56 & 2,80 & 3,09 & 3,00 & 3,08 & 2,14 & 2,78 & 2,14 & 3,09 & 2,90 & 0,34 & 3,06 \\
P5 & 2,56 & 2,50 & 3,09 & 1,83 & 3,08 & 2,15 & 2,54 & 1,83 & 3,09 & 2,53 & 0,46 & 2,95 \\
P6 & 1,06 & 2,00 & 2,91 & 0,00 & 2,62 & 0,14 & 1,46 & 0,00 & 2,91 & 1,53 & 1,14 & 2,47 \\
P7 & 2,00 & 1,50 & 3,09 & 2,18 & 2,83 & 2,00 & 2,27 & 1,50 & 3,09 & 2,09 & 0,54 & 2,67 \\
P8 & 2,00 & 1,50 & 3,09 & 1,67 & 2,67 & 1,23 & 2,03 & 1,23 & 3,09 & 1,84 & 0,66 & 2,50 \\
P9 & 1,89 & 2,00 & 3,09 & 2,00 & 2,62 & 1,43 & 2,17 & 1,43 & 3,09 & 2,00 & 0,54 & 2,47 \\
P10 & 3,00 & 3,20 & 3,09 & 2,77 & 3,23 & 2,86 & 3,03 & 2,77 & 3,23 & 3,05 & 0,17 & 3,17 \\
VGIC & 2,15 & 2,21 & 3,06 & 1,92 & 2,88 & 1,71 & 2,32 & 1,71 & 3,06 & 2,18 & 0,49 & 2,71 \\
\hline
\end{tabular}

Legenda: DP - desvio padrão; P75 - percentil 75; N - número de respondentes; VGIC - Valor Global do Índice de Comparabilidade.

Fontes: SIIUÉ. Elaboração dos autores. 
A média de respostas ao questionário de opinião da UC PIE é de 12. O maior VGIC ocorre no ano escolar de 2016 (3,06) e o menor em 2019 (1,71), tendo o valor de 2014 apenas dois abaixo de si (2017 e 2019). Assiste-se a um crescendo do VGIC entre o ano da entrada em funcionamento da UC PIE e 2016, para decrescer para valor ainda não alcançado antes, voltar a subir e afundar-se ainda mais em 2019. A importância da UC PIE para a aquisição de competências necessárias para o futuro exercício profissional (P10) congregou o maior IC (média 3,03), com expressão máxima no ano escolar de $2018(3,23)$, sendo o único item que ultrapassou a barreira do valor três. A coordenação entre docentes (P6) corresponde ao aspeto menos favorável, registando o valor médio de 1,46, único item com valor abaixo de dois. Parece, de facto, ser uma dificuldade que se arrasta desde a sua criação e já enunciada no trabalho de Amado (2014): em 2017 o valor é zero e em 2019 é de 0,14, ainda assim muito aquém do valor 1,06 relativo ao primeiro ano de execução desta UC. Segue-se a correspondência entre os conhecimentos avaliados e a matéria lecionada (P6), com valor de 2,03. A questão da avaliação também revela algumas opiniões negativas. Os métodos de avaliação utilizadas (P9) não receberam grande favoritismo $(2,17)$, todavia com alguma correspondência entre os conhecimentos avaliados e a matéria lecionada $(2,03)$.

No gráfico da Figura 1 apresenta-se a comparação dos valores globais do IC ao longo dos anos escolares de 2014-2019, das duas UC em apreciação.

Figura 1 - Comparação dos valores de VGIC, relativos aos anos escolares de 2014 a 2019, para a UC SDP e a UC PIE.

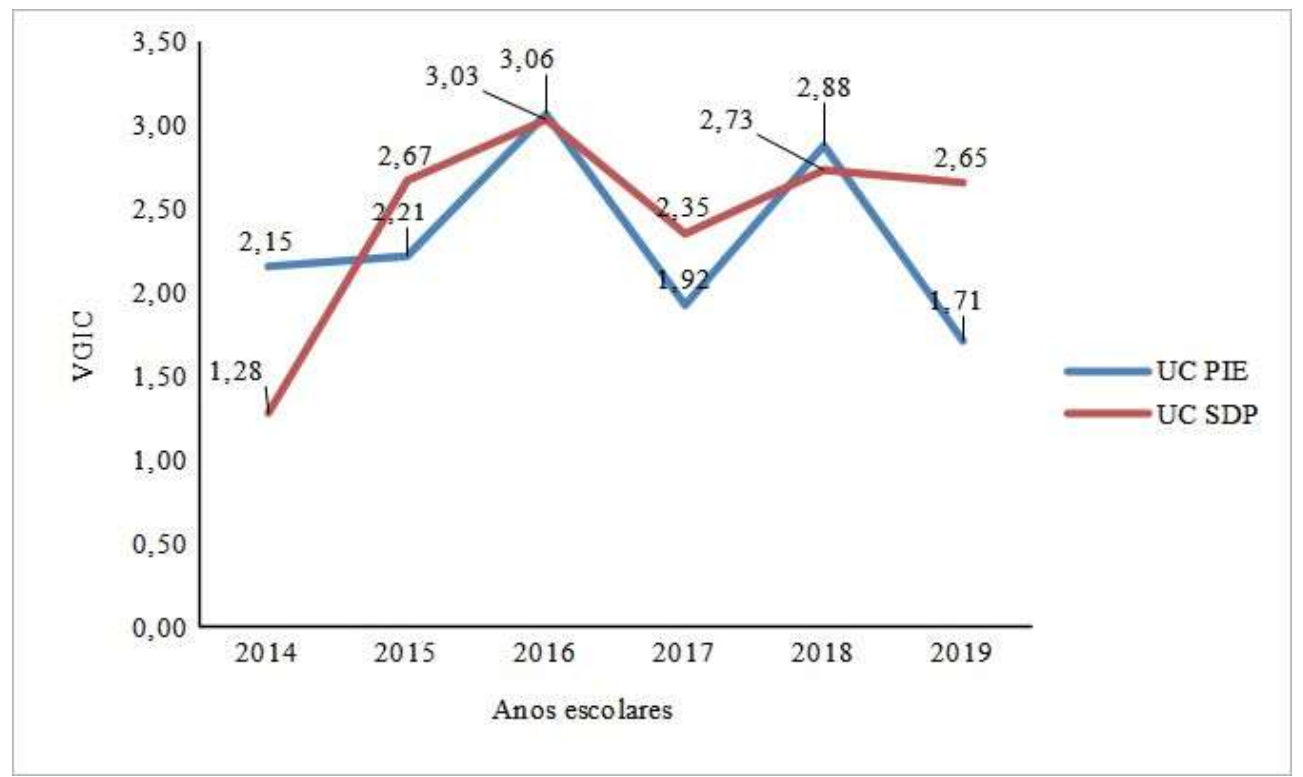

Não dispomos de elementos que nos permitam explicar causalmente a flutuação que se observa. Sendo que a UC SDP precede a da UC PIE, presumíamos que a acentuada experiência da IPP, associada ao maior conforto pela segurança do funcionamento da UC 
PIE permitisse gerar opiniões de maior VGIC. Mas não é isso que se verifica. Nestes 6 anos em apreciação, a média do VGIC da UC SDP é de 2,42, superior em 0,10 pontos ao VGIC da UC PIE. O corpo docente é relativamente estável nos últimos anos, variando unicamente a atribuição da sua coordenação. Inclinamo-nos para considerar que existe algum viés no momento da resposta ao inquérito. Os métodos de avaliação utilizados, por exemplo, são precisamente os mesmos na UC SDP e na UC PIE. Ainda assim, o valor deste item é superior na UC SDP em 0,16 pontos relativamente à UC PIE.

\subsection{A INICIAÇÃO À PRÁTICA PROFISSIONAL}

Na licenciatura em Ciências da Educação da UÉ, a IPP não se assumiu, desde o início, com esta designação. Segundo as linhas orientadoras da coordenação da UC PIE, pretendia-se que esta fosse uma disciplina de "aplicação", vocacionada para a intervenção multiforme em contextos educativos. Nesses termos, projetava-se que os alunos durante a UC SDP promovessem contactos com uma instituição de acolhimento cujo objeto do contrato social fosse a educação / formação para, na UC PIE, realizassem algumas horas no local de observação / intervenção. Não se encontravam definidos objetivos detalhados dessas observações / intervenções nem a definição da organização das mesmas. Na prática, a entidade acolhedora não tinha qualquer documento de suporte que lhe permitisse compreender o que a Universidade esperava de si e o que poderia aguardar dos alunos.

No ano escolar de 2017-2018, um dos autores deste trabalho assegurou funções letivas pela primeira vez na UC SDP. Engranzando nos fundamentos da UC PIE, projetou uma articulação mais profícua com a UC SDP, na qual os alunos iniciassem a sua intervenção multiforme precocemente, nesta última UC. Pensou-se que na UC SDP deveria haver um período de adaptação, mais de observação do funcionamento da entidade acolhedora para, no final desta e na UC PIE, existir um lugar específico para a intervenção.

A existência de um acordo que definisse as linhas orientadoras destas práticas nas UCs de SDP e PIE apresentava-se como elemento estruturante, no momento em que, apesar de revelar o que se esperava / pretendia, dava formalismo e seriedade à causa. Mas não só. Existem um conjunto de aspetos legais, como por exemplo, o seguro escolar, que só ficariam assegurados se existisse, efetivamente, um acordo entre as partes. Esse era já o pensamento de Amado (2014), quando destaca que se deveriam "estabelecer parcerias e assinar Protocolos" (p. 5).

No ano escolar de 2017 foi elaborado um acordo com este objetivo, por parte de um dos autores deste trabalho, que se viu vencido nas instâncias básicas de coordenação da UC. Foi necessário esperar pela mudança de coordenação das UCs, no ano escolar de 2018, para que fosse formalizada a IPP e aprovado um "Acordo de Definição das Linhas Orientadoras da IPP da Licenciatura em Ciências da Educação", firmado pelo órgão de Governo da UÉ, pela entidade de acolhimento e pelo aluno envolvido. Neste são definidos vários elementos acerca da IPP, em concreto: a) Natureza e âmbito; b) Objetivos / Compe- 
tências; c) Organização das observações e das intervenções; d) Instituição de acolhimento; e) Orientação / supervisão das observações e intervenções; f) Obrigações e direitos do aluno; $g$ ) Deveres da instituição de acolhimento; $h$ ) Avaliação dos desempenhos do aluno; i) Encargos; j) Resolução e denúncia; k) Vigência; l) Dúvidas e omissões.

Com a IPP pretende-se que as observações e intervenções constituam um momento / espaço de ensino e aprendizagem privilegiado na construção da identidade e do conteúdo funcional do técnico superior em ciências da educação, colocando ao alcance contactos em contexto profissional nas instituições públicas e privadas onde possam ser exercidas funções na área da educação / formação, facilitando o desenvolvimento de aprendizagens não adquiridas em contexto escolar, bem como a posterior integração do aluno na vida ativa. Deseja-se, ainda, facultar a aplicação e consolidação de aprendizagens efetuadas em contexto escolar pela execução de um múltiplo elenco de tarefas relacionadas com a formação técnica obtida e proporcionar a observação do funcionamento da instituição ou serviço específico da mesma, fomentando a capacidade de análise e reflexão sobre práticas de trabalho existentes.

O aluno deve desenvolver um conjunto de aprendizagens, com responsabilidade e autonomia técnica, ainda que com enquadramento superior qualificado e supervisionado, relativamente a capacidades, competências e atitudes adequadas ao contexto laboral, nomeadamente:

a) Exercer funções consultivas, de estudo, de planeamento, de programação, de avaliação;

b) Desenvolver a aplicação de métodos e processos de natureza técnica e ou científica inerentes à educação / formação, que visam fundamentar e preparar a decisão;

c) Elaborar, em colaboração, pareceres e projetos com diversos graus de complexidade;

d) Executar outras atividades de apoio geral ou especializado nas áreas de atuação comuns, instrumentais e operativas dos órgãos e serviços;

e) Desenvolver capacidade de comunicação (escrita e oral) entre os elementos da instituição e com terceiros.

f) No final das observações e intervenções, o aluno deverá apresentar as seguintes competências gerais:

g) Instrumentais (cognitivas, metodológicas, tecnológicas), referentes à organização do trabalho;

h) Interpessoais (individuais), relacionadas com a capacidade de interagir com os outros, de cooperação e trabalho em equipa e autonomia;

i) Sistémicas, relacionadas com a abordagem de diferentes contextos e situações de modo a compreender a sua complexidade e diversidade, com espírito crítico, sentido de responsabilidade, empenhamento; 
j) Outras (nomeadamente, assiduidade, pontualidade, atavio, cordialidade, assertividade, tolerância, compreensão, adaptação à mudança, vontade para a aprendizagem e para o aperfeiçoamento contínuo).

Por fim, augura-se, ainda, que o aluno apresente ter conhecimentos complementares, consoante o tipo de instituição de acolhimento, em algumas temáticas jurídicas (e.g., natureza e regime jurídico da instituição de acolhimento, Código do Procedimento Administrativo, Regime de Autonomia, Administração e Gestão Escolar, Código do Trabalho, Lei Geral do Trabalho em Funções Públicas, Regime Jurídico das Autarquias Locais).

$\mathrm{Na}$ UC SDP, das 96 horas de trabalho autónomo, 48 horas devem decorrer na instituição de acolhimento, numa média de 6 horas / semana, ao longo de 14 semanas. $\mathrm{Na}$ UC PIE o período de contacto com a instituição é de 84 horas, numa previsão de 8 horas / semana. No total, o aluno realiza 132 horas de IPP na instituição de acolhimento, facto que é mencionado no suplemento ao diploma.

É garantida ao aluno alguma liberdade para a procura e identificação da entidade de acolhimento, que melhor satisfaz as suas necessidades ou aspirações. Porém, segue-se o preceito de Amado (2014), em que "a opção de juntar alunos nas mesmas instituições não só empobrece desnecessariamente o leque de instituições-parceiras e o próprio leque de formação, mas deixa de fora instituições que temos ao dispor” (p. 5).

A gama de instituições de acolhimento nos últimos anos escolares tem sido variada e rica. Aliás, assistiu-se a uma generalizada aceitação da comunidade em acolher os alunos deste curso, o que constitui, no nosso ponto de vista, um primeiro fator importante da ligação Universidade-comunidade. A título de exemplo, para a IPP contou-se com: municípios (divisões de educação, bibliotecas); centros qualifica (e.g., Competir, Agrupamento de Escolas Gabriel Pereira); Exército (Direção de Formação); fundações (e.g., Fundação Eugénio de Almeida); Marinha (Direção de Formação; Gabinete de Tecnologia Educativa); Instituto do Desporto e da Juventude, IP; unidades de investigação (por exemplo, Centro de Investigação em Educação e Psicologia da UÉ), entre outras entidades. Os alunos dispõem, no início da UC SDP, de uma lista de entidades com relevo para a realização deste tipo de práticas.

A avaliação das aprendizagens da IPP é realizada à luz da triangulação de vários elementos, a saber: a) relatório das práticas multiformes em contextos educativos, validado pelo supervisor da instituição de acolhimento; b) apresentação e discussão do relatório, em plenário do grupo-turma; c) feedback fornecido pelo supervisor da instituição de acolhimento; d) elementos recolhidos nas tutorias entre o docente-tutor da Universidade e o aluno.

A avaliação da IPP é aqui discutida com base na triangulação entre elementos procedentes da avaliação realizada por alunos e aquela emanada das instituições de acolhimento. No ano escolar de 2019, foi solicitada, aos alunos da UC de PIE, uma avaliação da IPP, tendo por base uma análise SWOT. Responderam 7 alunas, representando $50 \%$ do total de alunos inscritos e $58,3 \%$ do sexo feminino. Os resultados apresentam-se na Tabela 3 . 
Tabela 3 - Resultados da análise SWOT realizada pelas alunas.

\begin{tabular}{|c|c|c|}
\hline \multicolumn{2}{|r|}{ Fatores positivos } & Fatores negativos \\
\hline & Forças & Fraquezas \\
\hline 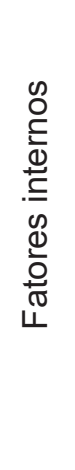 & $\begin{array}{l}\text { - Oportunidade de realizar a IPP e do contac- } \\
\text { to com o mundo do trabalho e dos profissio- } \\
\text { nais em educação. } \\
\text { - Possibilidade de escolher a instituição de } \\
\text { acolhimento. } \\
\text { - Diversidade de contextos / instituições ao } \\
\text { alcance do trabalho em educação / formação. } \\
\text { - Aquisição de conhecimentos e competên- } \\
\text { cias. } \\
\text { - Aquisição de prática profissional. } \\
\text { - Qualidade do acolhimento da instituição. }\end{array}$ & $\begin{array}{l}\text { - Falta de comunicação e coordenação } \\
\text { entre os docentes. } \\
\text { - Falta de assiduidade de um docente-tu- } \\
\text { tor. } \\
\text { - Horário das UCs pouco articulado com o } \\
\text { da IPP. } \\
\text { - Não ser equiparado a estágio curricular. } \\
\text { - Impossibilidade de se desenvolverem } \\
\text { determinadas atividades projetadas pelo } \\
\text { aluno. }\end{array}$ \\
\hline \multirow[b]{2}{*}{ 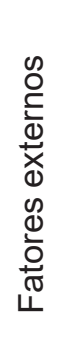 } & Oportunidades & Ameaças \\
\hline & $\begin{array}{l}\text { - Dar a conhecer às entidades acolhedoras o } \\
\text { curso de licenciatura em ciências da educação } \\
\text { para a possibilidade de virem a contratar profis- } \\
\text { sionais desta área. } \\
\text { - Dinamização de novas áreas. } \\
\text { - Desenvolvimento e consolidação de teletraba- } \\
\text { Iho, em função de um contexto de pandemia. }\end{array}$ & $\begin{array}{l}\text { - Lentidão do processo de aceitação de } \\
\text { algumas entidades de acolhimento. } \\
\text { - Realização da IPP em simultâneo com as } \\
\text { várias UCs do semestre. } \\
\text { - Distância física de algumas das entida- } \\
\text { des de acolhimento. }\end{array}$ \\
\hline
\end{tabular}

No que diz respeito aos supervisores das instituições de acolhimento, foi realizado o mesmo tipo de pedido, tendo por base uma análise SWOT. Responderam 8 instituições. Note-se que cada supervisor sentiu a IPP de um modo próprio, função das especificidade e vicissitudes internas. A síntese da análise dos resultados apresenta-se na Tabela 4. Sublinhe-se que alguns dos fatores aplicam-se concretamente a uma instituição de acolhimento e não de modo generalizado.

Tabela 4 - Resultados da análise SWOT realizada pelas instituições de acolhimento.

\begin{tabular}{|c|c|c|}
\hline \multicolumn{2}{|r|}{ Fatores positivos } & Fatores negativos \\
\hline & Forças & Fraquezas \\
\hline 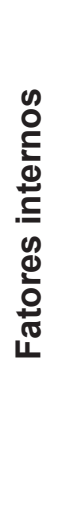 & $\begin{array}{l}\text { - Abertura da entidade de acolhimento à } \\
\text { comunidade académica, fortalecendo-se a } \\
\text { parceria entre o mercado de trabalho e a } \\
\text { instituição académica. } \\
\text { - Diversidade de práticas educativas. } \\
\text { - Trabalho que envolve fases diversas } \\
\text { (planeamento, operacionalização e moni- } \\
\text { torização / avaliação) de ações e projetos } \\
\text { educativos. } \\
\text { - Experiência da supervisora. } \\
\text { - Apoio no desenvolvimento de projetos e } \\
\text { atividades. }\end{array}$ & $\begin{array}{l}\text { - Tempo insuficiente para discussão dos assuntos e } \\
\text { para assimilação da cultura institucional. } \\
\text { - Avolumado empenhamento em tarefas internas sem } \\
\text { espaço para supervisão ativa da IPP. } \\
\text { - Poucas oportunidades para tarefas mais práticas, } \\
\text { de experimentação das propostas. } \\
\text { - Necessidade de reformular o projeto inicial, face ao } \\
\text { contexto Covid-19, implicando mais tempo despendi- } \\
\text { do nas tarefas que o aluno teria que executar. }\end{array}$ \\
\hline
\end{tabular}




\begin{tabular}{|c|c|c|}
\hline \multirow[t]{2}{*}{ 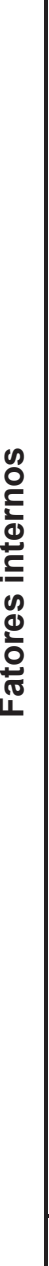 } & $\begin{array}{l}\text { - Partilha de conhecimentos e experiência e } \\
\text { a integração natural de conhecimentos oriun- } \\
\text { dos de diferentes áreas do saber. } \\
\text { - Tempo de contacto muito razoável. } \\
\text { - Boa conjugação de interesses entre o for- } \\
\text { mando e a entidade de acolhimento. } \\
\text { - A IPP direciona o aluno para uma profissio- } \\
\text { nalidade ativa e interativa. } \\
\text { - Fornecimento de instrumentos de análise } \\
\text { do real, com a incorporação de boas práticas } \\
\text { na organização pessoal e profissional. } \\
\text { - Preparação para a tomada de decisões em } \\
\text { situações particulares e não generalizadas. } \\
\text { - Articulação teoria / prática. } \\
\text { - Enriquecimento pessoal através da experi- } \\
\text { ência profissional. } \\
\text { - Novas perspetivas ("sangue-novo") que o } \\
\text { aluno traz. } \\
\text { - Potenciar a dinâmica e estratégia social da } \\
\text { organização. } \\
\text { - Possibilidade pela integração do aluno na } \\
\text { organização. } \\
\text { - Criação de oportunidades de mentoria para } \\
\text { os trabalhadores da entidade. } \\
\text { - Fortalecimento da parceria entre a entidade } \\
\text { de acolhimento e a Universidade. } \\
\text { - Comportamento do aluno: assiduidade, dis- } \\
\text { ponibilidade, integração na equipa, espírito } \\
\text { de iniciativa. }\end{array}$ & $\begin{array}{l}\text { - Controlo da assiduidade e pontualidade dos alunos. } \\
\text { - Incompatibilidade com especificidades técnicas do } \\
\text { desempenho funcional. } \\
\text { - Plano de trabalho pouco aberto às necessidades da } \\
\text { instituição de acolhimento. } \\
\text { - Definição pouco clara dos objetivos que os alunos } \\
\text { devem alcançar. } \\
\text { - Desconhecimento da dinâmica e das atividades da } \\
\text { organização, face à sua complexidade e às ativida- } \\
\text { des desenvolvidas; } \\
\text { - Período de adaptação moroso e complexo. } \\
\text { - Gestão cautelosa de informação de cariz reservado } \\
\text { ou confidencial. } \\
\text { - Conhecimentos ainda pouco consolidados }\end{array}$ \\
\hline & Oportunidades & Ameaças \\
\hline & $\begin{array}{l}\text { - Otimizar momento para edificar tarefas que } \\
\text { não poderão ser realizadas de outra forma. } \\
\text { - Colaboração próxima e complementar entre } \\
\text { os meios académico e profissional. } \\
\text { - Formação mais enriquecedora dos alunos, } \\
\text { para integrar o mercado de trabalho. } \\
\text { - Rentabilização de produtos elaborados por } \\
\text { alunos. } \\
\text { - Acesso a novos conhecimentos e ideias. } \\
\text { - Partilha da experiência profissional com } \\
\text { futuros profissionais da área. } \\
\text { - Atração de potenciais empregadores, com } \\
\text { o desenvolvimento de uma rede de contac- } \\
\text { tos (networking). } \\
\text { - Divulgação da licenciatura em ciências da } \\
\text { educação pela comunidade, com atração de } \\
\text { potenciais parcerias. } \\
\text { - Partilha de conhecimentos. }\end{array}$ & $\begin{array}{l}\text { - Trabalho muito focado no historial da entidade de } \\
\text { acolhimento, em vez de se centrar nas necessidades } \\
\text { da entidade. } \\
\text { - Diferentes intenções dos envolvidos. } \\
\text { - Distanciamento físico em contexto de Covid-19, } \\
\text { mantendo o aluno sempre a sua disponibilidade, mas, } \\
\text { ainda assim, dificultando o seu acompanhamento. } \\
\text { - Pouco tempo e necessidade de maior preparação } \\
\text { para a produção de recursos de qualidade que pos- } \\
\text { sam ser rentabilizados. } \\
\text { - Condicionamentos na escolha da entidade por falta } \\
\text { de apoios nos deslocamentos. } \\
\text { - Desconhecimento dos avaliadores sobre o contexto } \\
\text { institucional poderá ter implicações na avaliação do } \\
\text { aluno. } \\
\text { - Desconhecimento das entidades no que diz respeito } \\
\text { à licenciatura em ciências da educação e ao papel } \\
\text { destes alunos na sua organização. } \\
\text { - A absorção dos alunos nas entidades de acolhimen- } \\
\text { to após o fim de uma IPP parece reduzida. } \\
\text { - Limitações nos processos de recrutamento das } \\
\text { organizações / instituições. } \\
\text { - Exigências de funcionamento e de cumprimento de } \\
\text { procedimentos externas à entidade de acolhimento. } \\
\text { - Distância geográfica entre as entidades de acolhi- } \\
\text { mento e a instituição académica. }\end{array}$ \\
\hline
\end{tabular}




\section{CONSIDERAÇÕES FINAIS}

A formação de profissionais com competências para desempenhar funções técnicas em contextos diversos, cujo denominador comum seja a educação, no âmbito de uma licenciatura em ciências da educação, revela-se, para as instituições formadoras, uma tarefa conceptual e operacional particularmente complexa. No atual enquadramento legal das formações, a inserção de um espaço dedicado à IPP, permitindo, por um lado, que as aprendizagens realizadas possam ser mobilizadas em contexto real e, por outro, o acesso a esse mesmo contexto, traduz-se num primeiro contacto com a realidade do mercado de trabalho, que tem vindo a ganhar consistência. A experiência do percurso que, neste plano, tem sido trilhado na licenciatura em ciências da educação da UÉ aponta para essa necessidade.

A possibilidade de, por parte dos alunos, poderem perspetivar um amplo conjunto de funções para as quais estão qualificados e, assim, ampliarem a sua visão do mercado de trabalho, ocorre, nestes espaços curriculares, de forma privilegiada. Igualmente, do ponto de vista dos potenciais empregadores, o contacto com estes estudantes e a sua integração nas dinâmicas das instituições, públicas e/ou privadas, com distintos âmbitos de atuação e relação com as comunidades em que se inserem, sobretudo se consolidado por uma relação consistente com a instituição formadora, formalizada em moldes que possibilitem o reforço do estatuto de parceiros na formação, estes alunos assumem, com crescente nitidez, o papel de valiosos potenciais recursos. Como refere Amado (2014), "a empregabilidade dos alunos diplomados é um fator na avaliação do Curso e, claro, sabemos que independentemente de qualquer motivo institucional é importante aumentar a probabilidade de se vir a fazer com sucesso e tão depressa quanto possível, a inserção profissional dos diplomados" (p. 5). E por isso, continua o autor, acredita que "depende nalguma medida da qualidade da aproximação ao 'terreno' que for conseguida no curso e, designadamente nestas duas UCs do ano terminal do curso" (p. 5).

A margem de perfetibilidade neste processo, trabalhada nos diversos momentos de avaliação do curso, potenciando os aspetos valorados como mais positivos e trabalhando no sentido de mitigar e/ou eliminar a vulnerabilidade face aos constrangimentos identificados, nos diversos planos de análise considerados, dependerá, sobretudo, da assertividade colocada nas dinâmicas que permitirão aprofundar e consolidar a rede de entidades parceiras, algo que tem vindo a ser conseguido. Em plano diverso, mas requisito prévio essencial, é evidente a necessidade de melhoria das dinâmicas internas, que potenciarão a qualidade global dos processos, nomeadamente a articulação entre as UCs nas quais, ao longo do curso, são realizadas aprendizagens a mobilizar na hora de aceder aos contextos de trabaIho nas instituições parceiras.

Ainda neste plano, e estando a IPP alocada às duas UCs SDP e PIE, será importante o trabalho sobre o que é percebido como alguma dificuldade de articulação entre os membros das equipas docentes. Para além dos desafios que a constituição de equipas 
docentes sempre coloca, o facto de, nestas duas UCs os docentes serem convocados a promover dinâmicas de âmbito e natureza diversa, incluindo o estabelecimento de pontes entre as entidades de acolhimento, exteriores à Universidade, potencia a possibilidade de dispersão e de menor integração. O papel das estruturas de coordenação, nomeadamente das Comissões Executivas e de Acompanhamento do curso, enquanto plataformas de monitorização constante da qualidade dos processos, integrando a reflexão sobre os dados que o sistema interno de qualidade fornece, mobilizando e promovendo práticas de partilha entre pares no seio do corpo docente e dinamizando ações que progressivamente visem a agilização e credibilização da interação entre a Universidade e a comunidade na qual as entidades formadoras estão sediadas é, neste campo, determinante.

\section{AGRADECIMENTOS}

Este trabalho é financiado por fundos nacionais através da FCT - Fundação para a Ciência e a Tecnologia, IP, no âmbito dos projetos UIDB/04312/2020 e UID / CED / $00194 / 2013$. 


\section{REFERÊNCIAS}

AMADO C. Carta dirigida aos alunos inscritos na unidade curricular de Seminário de Desenvolvimento de Projetos e aos colegas docentes. Arquivo pessoal de Jorge Bonito, Évora, Portugal, 18 nov. 2014.

CASH A; WILLIAMS J; HART L. University-district partnerships to improve field experiences: Associations with candidate perceptions and performance. Teaching and Teacher Education, v. 94, p. 103-22, 2020. Disponível em: https://www.sciencedirect.com/science/article/abs/pii/ S0742051X19311114. Acesso em: 03 dez. 2020.

CE - COMISSÃO EUROPEIA. Educação e Formação. Disponível em: https://ec.europa.eu/education/resources-and-tools/european-credit-transfer-and-accumulation-system-ects_pt. Acesso em: 03 dez. 2020.

COLÁS MP. La metodología cualitativa. In: COLÁS, MP; BUENDÍA L (Orgs.), Investigación educativa (3. ${ }^{a}$ ed.). Sevilla, España: Alfar. 1988, p. 249-90.

FARIAS, IMS; SILVA, SP. Ensinar na docência universitária: indícios da integração ensino e pesquisa. Cadernos de Pesquisa, v. 21, n. 3, p. 68-81, 2014. Disponível em: www.periodicoseletronicos. ufma.br/index.php/cadernosdepesquisa/article/view/3073/1579. Acesso em: 03 dez. 2020.

GALLOWAY L; MARKS A; CHILLAS S. The use of internships to foster employability, enterprise and entrepreneurship in the IT sector. Journal of Small Business and Enterprise Development, vol. 21, n. 4, p. 653-67, 2014. Disponível em: https://research-repository.st-andrews.ac.uk/handle/10023/5937. Acesso em: 03 dez. 2020.

GARCÍA-ARACIL A; MONTEIRO S; ALMEIDA L. Students' perceptions of their preparedness for transition to work after graduation. Active Learning in Higher Education, 2018. Disponível em: https://journals.sagepub.com/doi/abs/10.1177/1469787418791026?journalCode=alha. Acesso em: 03 dez. 2020.

GLADWELL M. Outliers. Lisboa: Publicações Dom Quixote, 2008.

GPGUÉ - Gabinete de Planeamento e Garantia da Universidade de Évora. Manual de qualidade do sistema interno de promoção e garantia da qualidade na Universidade de Évora. Évora, Portugal, 2014. Universidade de Évora. Disponível em: http://gdoc.uevora.pt/422593. Acesso em: 03 dez. 2020.

HOLYOAK L. Are all internships beneficial learning experiences? An exploratory study. Education + Training, vol. 55, n. 6, 573-583, 2013. Disponível em: http://clok.uclan.ac.uk/8206/. Acesso em: 03 dez. 2020.

ISMAIL Z. Benefits of Internships for Interns and Host Organisatiosn. Heldesk Report. K4D - Knowledge, evidence and learning for development, 2018. Disponível em: https://assets.publishing. service.gov.uk/media/5b3b5de3ed915d33c7d58e52/Internships.pdf. Acesso em: 03 dez. 2020.

KAUFMAN J. The Personal MBA. London: Penguin Books, 2012.

MAERTZ C; STOEBERL P; MARKS J. Building successful internships: lessons from the research for interns, schools, and employers. Career Development International, vol 19, n. 1, p. 123-42, 2014. Disponível em: https://www.emerald.com/insight/content/doi/10.1108/CDI-03-2013-0025/full/ html. Acesso em: 03 dez. 2020. 
MCMANUS A; FEINSTEIN AH. Internships and Occupational Socialization: What are Students Learning? Developments in Business Simulation and Experiential Learning. Proceedings of the Annual ABSEL Conference, vol. 35, n. 0, 2014. Disponível em: https://www.researchgate.net/publication/239847425_Internships_and_occupational_socialization_What_are_students_learning.

Acesso em: 03 dez. 2020.

PLUM S. An Authentic Connection to Learning. Out-of-school experiences for high schoolers foster purpose and belonging. Edutopia, 2018. Disponível em: https://www.edutopia.org/article/authenticconnection-learning. Acesso em: 03 dez. 2020.

SANITER N; SIEDLER T. Door Opener or Waste of Time? The Effects of Student Internships on Labor Market Outcomes. IZA Discussion Papers 8141. Institute for the Study of Labor (IZA), 2014. Disponível em: https://ideas.repec.org/p/iza/izadps/dp8141.html. Acesso em: 03 dez. 2020.

SILVA K; BELO J. A importância do estágio supervisionado em serviço social: uma experiência na unidade de atenção à saúde da criança e do adolescente do hospital universitário professor Alberto Antunes. GEPNEWS, vol. 2, n. 2, p. 564-72, 2019. Disponível em: https://www.seer.ufal.br/index. php/gepnews/article/view/7953. Acesso em: 03 dez. 2020.

ŠIMIČEVIČ D; ŠTETIĆ S. The role and importance of internship programs as part of formal educa- tion: students' perceptions - the case of college of tourism. Turisticko poslovanje, 19, 51-60, 2017. Disponível em: https://scindeks-clanci.ceon.rs/data/pdf/0354-3099/2017/0354-30991719051S.pdf. Acesso em: 03 dez. 2020.

UÉ - UNIVERSIDADE DE ÉVORA. Anexo 1. NCE/11/01581 - Apresentação do pedido - Novo ciclo de estudos. Évora: Universidade de Évora. Disponível em: http://gdoc.uevora.pt/310302. Acesso em: 03 dez. 2020.

UÉ - UNIVERSIDADE DE ÉVORA (2012b). Anexo 2. Licenciados em Ciências da Educação. Listagem de funções e empregadores. Évora: Universidade de Évora, 2012b. Disponível em: http://gdoc.uevora.pt/310302. Acesso em: 03 dez. 2020.

UÉ - UNIVERSIDADE DE ÉVORA. Anexo 3. Projetos de Intervenção em Educação - versão 1 (05/07/2011). Évora: Universidade de Évora, 2012c. Disponível em: http://gdoc.uevora.pt/310302. Acesso em: 03 dez. 2020.

UÉ - UNIVERSIDADE DE ÉVORA. PERA/1718/1101581. Relatório final da CAE. Évora: Universidade de Évora, 2012d. Disponível em: http://gdoc.uevora.pt/586984. Acesso em: 03 dez. 2020.

UL - Universidade de Lisboa. Licenciatura em Educação e Formação, 2020. Disponível em: http://www.ie.ulisboa.pt/ensino/licenciatura-educacao-formacao. Acesso em: 03 dez. 2020.

US - University of Suffolk. Developing Professional Practice, 2020. Disponível em: https://www. uos.ac.uk/content/developing-professional-practice. Acesso em: 03 dez. 2020.

Vélez GS; Giner GR. Effects of Business Internships on Students, Employers, and Higher Education Institutions: A Systematic Review. Journal of Employment Counseling, vol. 52, n. 3, p. 121-30, 2015. Disponível em: https://onlinelibrary.wiley.com/doi/abs/10.1002/joec.12010. Acesso em: 03 dez. 2020. 